\title{
Research on High-voltage Switchgear Multi-parameter Monitoring System
}

\author{
Fenghong $\operatorname{Pan}^{1, a *}$ and Jianjun $\operatorname{Lan}^{2, b}$ \\ ${ }^{1}$ School of Mechanical Engineering, Jilin Institute of Chemical Technology, Jilin, China \\ ${ }^{2}$ School of Automation Engineering, Northeast Dianli University, Jilin, China \\ a7612254@qq.com, ${ }^{b} 16703967 @ q q . c o m$
}

Keywords: Switch cabinet; Temperature; Humidity; Travel; Over travel

\begin{abstract}
The sensor SHT11 was used in measurement of temperature and humidity inside the high voltage switchgear cabinet, by the resistance sensor as displacement sensor, the method of mechanical parameter measurement for the breaker was put forward. Using the resistance sensor, got the breaker's characteristic curves of displacement-time and velocity-time, and completed the calculation of breaker's travel; overtravel, closing speed, opening speed and number of switching. The method can measure the various parameters of beaker in efficiency; the result shows that this method has a good application prospect in the advantages of increasing measure precision and reducing measurement times.
\end{abstract}

\section{Introduction}

With the development of national economy, customers become stricter with the power quality and automation of the power system, higher and higher technologies are required for reliability of high voltage switch cabinet. Running status of on-line monitoring of switch cabinet becomes more and more necessary, at the same time request for monitoring devices of parameter detection must be safe and reliable operation, and prevent it from becoming additional fault. By using monitoring system, user can correct potential problems in time and forecast the possible faults to estimate, it is essential to the normal operation of switch cabinet.

At present, photoelectric sensor is more and more applied in mechanical parameter measurement of switch cabinet $[1,2]$, by using the position of moving contact, so as to calculate the relevant parameters indirectly [3,4]. Although the photoelectric sensor has the advantages of small volume, light weight and fast response time, it has the fatal disadvantages of high cost, low accuracy and is unable to decision of start point of over travel directly[5, 6].

The design measures the displacement of moving contact by using resistive linear displacement sensor, it is response is instant, and gets the other characteristics of the break by calculated method indirectly. The sensor has advantages of low cost, high precision, and can be used to measure the parameters of the most high voltage circuit breaker.

\section{System Summary}

Main Failure of Switch Analysis. After long term operation of the cabinet, for various reasons, it influences electrical power system normal operation because of self-malfunction, the main faults are mainly consisted of higher contact resistance on the increase, creepage distance reducing, and contact finger to wear. The above questions may cause a single breaker failure even the whole system paralysis, which caused the huge pecuniary loss to the enterprise and has a potential impact on our staff's safety.

System Monitoring Parameters and Requirements. Causes for the above mentioned defects were analyzed, simultaneously, in order to estimate the fatigue life of the breaker, the monitoring system need to measure the parameters as follows: Temperature and humidity of switch cabinet, travel and over travel of breaker, closing speed and opening speed, number of times of breaker off and 
on. And because the surrounding environment inside the switch cabinet is complicated, the monitoring system needs a high anti-jamming ability.

\section{System Design}

Taking the parameter to monitor and desire into consideration, the paper conducts the research on the following issues: the first is the selection of sensor for the detection of temperature and humidity in switch cabinet, another is the selection of suitable displacement sensor, and the travel, over travel and switch-on or switch-off speed can be calculated by output end of the displacement sensor indirectly. The system can send the various parameters to the display device and upload data through communication interface. The total block diagram of system is shown in Fig. 1.

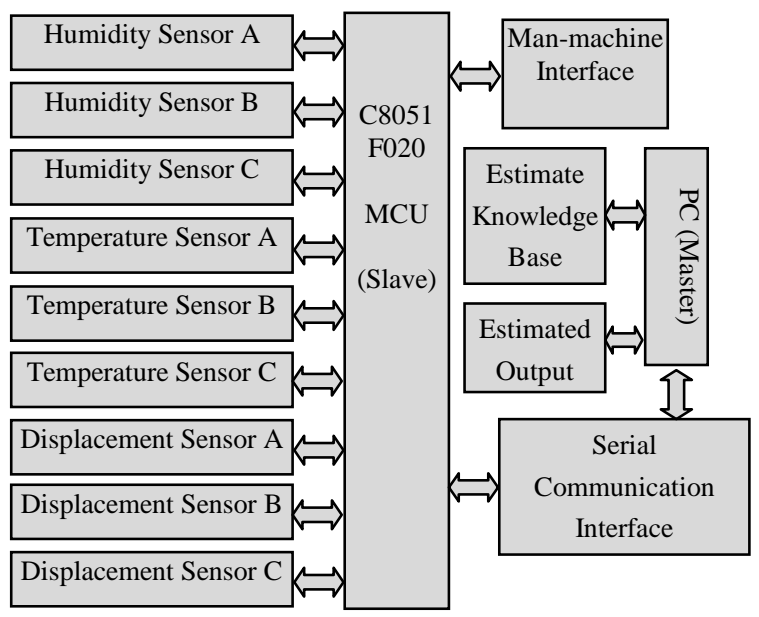

Figure 1. The System Configuration

Hardware Design. The C8051F020 is chooses for host, which has the specialty of on-chip $\mathrm{I}^{2} \mathrm{C}$ interface, on-chip 10-bit A/D converter with $100 \mathrm{KS} / \mathrm{s}$ sampling rate, on-chip watchdog timer and on-chip temperature sensor.

Multiple sensors can be used for detection of temperature and humidity; most of them are expensive in cost, low in reliability, easily distracted and rigorous requirement of environment. SHT11 is used for measuring relative humidity while temperature is measured by a band-gap sensor. The applied CMOSens ${ }^{\circledR}$ technology guarantees excellent reliability and long term stability. Both sensors are seamlessly coupled to a 14bit analog to digital converter and a serial interface circuit. This results in superior signal quality, a fast response time and insensitivity to external disturbances (EMC). Measure of mechanical parameters was performed by the carbon resistor TRS50, the sensor was installed on the insulated tension pole; the connection mode was shown in Fig. 2.

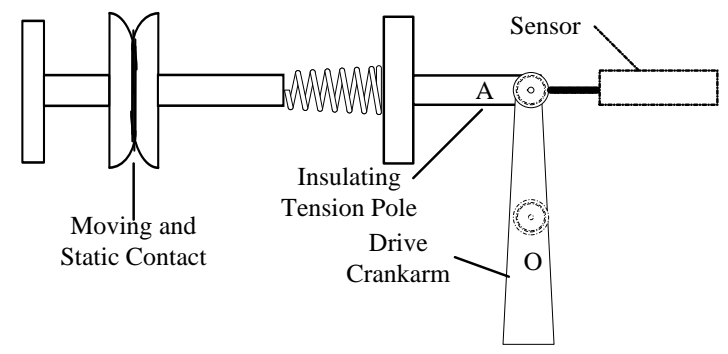

Figure 2. The Connection Mode of The Displacement Sensor

In order to realize human-machine interaction, consideration for real-time, the system sets four independent buttons with the interruption of work; display circuit chooses LCM12864ZK used to display various parameters. Client transmit the data to the host by communication interface, using the 
related data and knowledge base, the host estimates the life of the high voltage circuit breaker by artificial neural network (ANN) [7, 8].

Software Design. The measurement of travel, overtravel, and average speed were performed by the displacement sensor. The measure was the displacement-time curve at the insulated tension pole. In the procedure of contact moving, the displacement-time curve could be drawn by sampling the displacement sensor outputting signal.

For the vacuum circuit breaker whose erosion of contact cannot be directly measured, the erosion of contact can be calculated by accumulated variation of overtravel [9-10], and by them the residual electrical life can be calculated indirectly. And the relationship changed, as the open distance of contact was adjusted, so residual electrical life can be estimated by upper computer based on the input of various parameters by the neural network model.

\section{Experiment and Analysis}

Experimental Data.The breakers worked at $40.5 \mathrm{kV}$, the travel was $25 \pm 1 \mathrm{~mm}$ and the overtravel was $6 \pm 1 \mathrm{~mm}$. The measure precision was $0.2 \mathrm{~mm}$. The sampling rate should not less than $5 \mathrm{kHz}$. In order to validate the feasibility and measuring accuracy of this project, the experiments were done in the breakers which type was ZN107-40.5. According to the experimental data output from displacement sensor, the displacement-time and speed-time curves are obtained, the particulars was shown in Fig. 3 and Fig. 4. In the displacement-time and speed-time curve, the point $\mathrm{T} 1$ was the touch time of the moving contact and the static contact. The velocity measured decreased at this inflexion point. At T2 point in the time axis, the velocity reached the maximum point and after this time, the velocity changed from zero to negative value. The detailed data of mechanical parameter was shown in Tab.1.

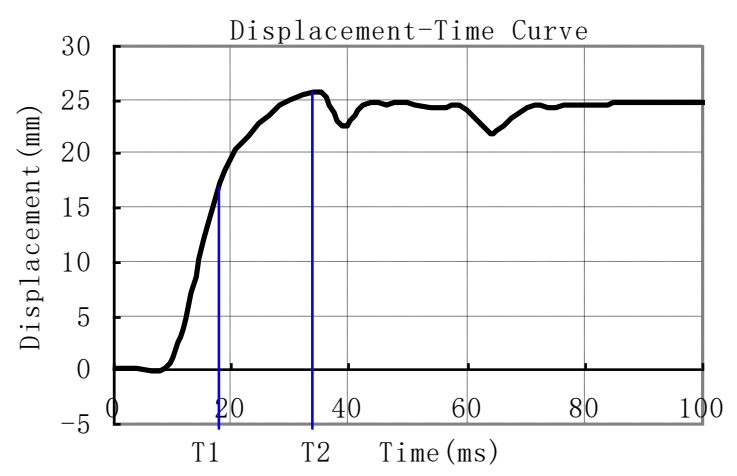

Figure 3. Displacement-Time Curve

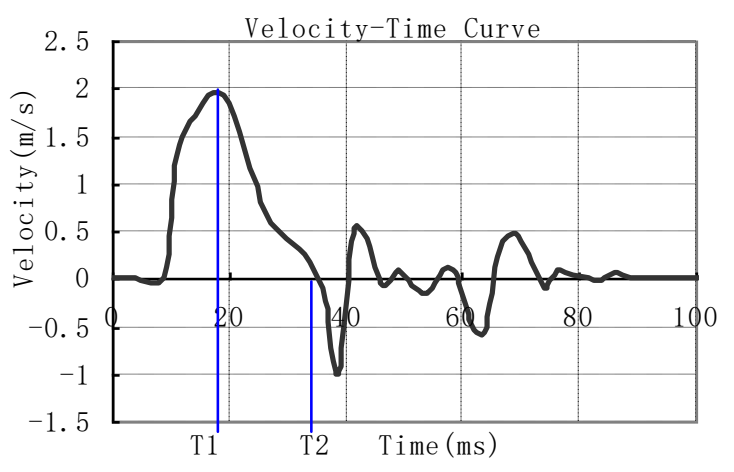

Figure 4. Velocity-Time Curve

The experiment results show that the relative mechanical parameter of breaker can be measured within the allowed accuracy range by this method, and this research method is more efficient than the other ones in terms of cost and installation convenience.

Table 1 Measurement Data Analysis

\begin{tabular}{ccccc}
\hline Items & $\begin{array}{c}\text { Technical } \\
\text { Standard }\end{array}$ & $\begin{array}{c}\text { Factory } \\
\text { Value }\end{array}$ & $\begin{array}{c}\text { Measured } \\
\text { Value }\end{array}$ & Error \\
\hline Travel & $19 \pm 1 \mathrm{~mm}$ & 18.59 & 18.48 & $0.31 \%$ \\
Overtravel & $6 \pm 1 \mathrm{~mm}$ & 6.68 & 6.79 & $1.11 \%$ \\
Closing Speed & $1.5 \pm 0.2 \mathrm{~m} / \mathrm{s}$ & 1.53 & 1.55 & $1.30 \%$ \\
Opening Speed & $1.0 \pm 0.2 \mathrm{~m} / \mathrm{s}$ & 1.12 & 1.14 & $1.78 \%$ \\
Closing Time & $\leq 100 \mathrm{~ms}$ & 94 & 94.8 & $0.85 \%$ \\
Opening Time & $\leq 60 \mathrm{~ms}$ & 55 & 55.6 & $1.09 \%$ \\
\hline
\end{tabular}


Error Analysis.The motion locus of point A was shown in Fig. 2, according to the sensor unit location map which was shown in Fig. 5. When point A moves to the point A', the actual displacement is $l$, instead of the displacement in the perpendicular direction $x$, this will certainly to cause the error $\Delta x$ to the measurement. The relation equation between $l$ and $x$ is derived through Fig. 5 as Eq. 1.

$$
\Delta x=x-l-l^{2} / 2 r
$$

The $r$ of this breaker for testing is $267 \mathrm{~mm}$, if $l$ is $25 \mathrm{~mm}$, then $x$ is $24.97 \mathrm{~mm}$, the error $\Delta x$ is $0.034 \mathrm{~mm}$ which can be calculated according the Eq.1, and meets the requirement of measurement accuracy.

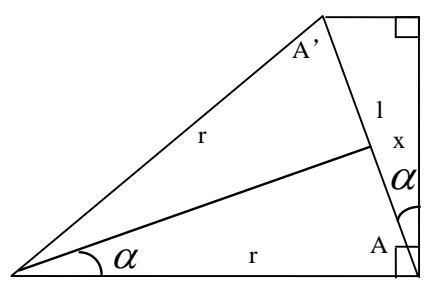

Figure 5. Measure Point Motion Curve

\section{Conclusion}

Because measurement of the mechanical parameter is difficult, and the measuring accuracy is low, using the resistive displacement sensor for displacement measurement, the hardware and software design of system are discussed in detail. At last a test of the system is given on the high voltage circuit breaker. The data shows that this scheme is feasible and suitable for measuring of most breakers, and it can meet the requirement of measurement accuracy. It has great significance for high voltage circuit breaker field maintenance and working position judgment.

\section{References}

[1] Y.D. Fang: Electric Switchgear, (2006) No.2, p. 31. (In Chinese)

[2] Q. Duan, F.X. Li and Z.L. Tian: Low Voltage Apparatus, (2008) No.21, p. 52. (In Chinese)

[3] Z.G. Xu: Principle and Application of High-voltage Switchgear (Tsinghua University Press, China 2000), p. 68. (In Chinese)

[4] J. Huang, X.G. Hu and Y.N. Gong. Journal of Electrical and Control, (2011) No.10, p.35. (In Chinese)

[5] Q.Y. Ye and W.J. Dai: Jiangxi Electric Power, Vol. 25 (2001) No.1, p. 9. (In Chinese)

[6] J. Li and J. Wu: Microcomputer Information, Vol. 23 (2007) No.10, p. 134. (In Chinese)

[7] L.J. Sun and X.G. Hu: Power System Technology, (2006) No.12, p. 476. (In Chinese)

[8] C.H. Zhang: Jilin Electric Power, (1999) No.5, p. 40. (In Chinese)

[9] Y. Wang, Z.L. Piao and X.M. Wang: Journal of Shenyang Agricultural University, (2005) No.2, p. 250. (In Chinese)

[10]X.S. Guo and Z.Q.Wang: High Voltage Engineering, (1999) No.2, p. 43. (In Chinese). 